\title{
Autonomia privada e paternalismo estatal: a necessidade de políticas públicas preventivas para alteração do paradigma público-privado
}

\author{
Private autonomy and state paternalism: the need of \\ preventive public policies for amendment of public- \\ private paradigm
}

\author{
Felipe da Veiga Dias* \\ Jorge Renato dos Reis
}

\section{Resumo}

O presente estudo, cujo tema central é o conflito entre autonomia privada e paternalismo estatal, com enfoque na tentativa de traçar um limite às intervenções estatais, tem como panorama propositivo as políticas públicas para prevenir ações invasivas, buscando ofertar novas soluções a algumas demandas sociais. Portanto, questiona-se acerca da possibilidade de esses parâmetros trazerem novos suportes a antigos conflitos, os quais têm efeitos públicos e privados. Desse modo, o objetivo desta pesquisa é delimitar a intervenção do Estado (principalmente o de índole paternalista) na esfera da autonomia privada, a fim de determinar os rumos do desenvolvimento da personalidade humana na sociedade contemporânea. Posto isso, as proposições de políticas públicas,

Doutorando e mestre em Direito pela Universidade de Santa Cruz do Sul (UNISC). Especialista em Direitos Fundamentais e Constitucionalização do Direito (PUC/RS). Professor da Faculdade Metodista de Santa Maria (FAMES). Integrante do Grupo de Estudos em Direitos Humanos de Crianças, Adolescentes e Jovens do Núcleo de Pesquisa Políticas Públicas de Inclusão Social (GRUPECA/UNISC). Participante do projeto de pesquisa "A violência intrafamiliar contra crianças e adolescentes e as políticas públicas: a imperiosa análise do problema para o estabelecimento de parâmetros de reestruturação do combate às violações aos direitos infanto-juvenis" (CNPQ). Advogado. Santa Maria - RS - Brasil. E-mail: felipevdias@gmail.com

* Pós-doutor em Direito pela Universidade de Salerno - Itália, Professor do Programa de PósGraduação em Direito (Mestrado e Doutorado) da UNISC. Coordenador dos projetos "Políticas públicas de educação para o consumo" e "O direito de autor no constitucionalismo contemporâneo: um estudo comparado Brasil x Uruguai". Coordenador dos grupos de estudos e pesquisas (CNPQ) "Intersecções jurídicas entre o público e o privado" e "Direito de autor". Advogado. Santa Cruz do Sul-RS - Brasil. E-mail: jreis@viavale.com.br 
com base em uma visão constitucionalizada, objetivam uma direção oposta àquelas apresentadas atualmente em relação às mesmas situações fáticas. Alguns desses casos são referidos, como os jogadores compulsivos e as casas de prostituição. Por fim, cabe aduzir que este estudo tem como método de abordagem o dedutivo, e como método de procedimento, o monográfico, combinando-se ao final com a técnica de pesquisa de bibliografia indireta.

Palavras-chave: Autonomia privada. Paternalismo estatal. Políticas públicas.

\section{Abstract}

This study has as central theme the conflict between private autonomy and state paternalism, focusing more specifically the attempt to trace limit state intervention, with the panorama purposeful public policy to prevent invasive actions, seeking new solutions to offer some social demands. Therefore, if questioned about the possibility of these parameters bring new support to old conflicts, which has effects both public and private. Thus the aim of this research is original, that is, these are the first steps in deepening the study, trying it define some limits on state intervention (mainly paternalistic indole), which invade the sphere of private autonomy in order to determine the direction of development of the human personality in contemporary society. That said, the propositions, based on a constitutionalized vision public policy aim a direction opposite to those presented today in relation to the same factual situations, some of these cases are referred to - such as compulsive gamblers and (houses of) prostitution - in other words, aim up new solutions to old demands. Finally it is adduced that the present study is the deductive method of approach, and the monographic procedure, combining the end with the technique of indirect research bibliography.

Keywords: Private autonomy. Paternalism state. Public policy.

\section{Introdução}

O tema deste estudo é a autonomia privada e o seu conflito com o paternalismo estatal. Porém, buscando uma maior delimitação, infere-se que é a busca do estabelecimento de limites à intervenção estatal, a fim de auferir um caminho para a implementação de políticas públicas de natureza preventiva, ligadas à resolução de problemas de cunho público 
e, ao mesmo tempo, privado. Assevera-se que tal proposta tem cunho modificativo, haja vista que a postura estatal em relação às situações abordadas é de pura restrição, sem concessões.

O antagonismo entre autonomia privada e paternalismo não se apresenta de maneira absoluta, havendo espaços de harmonia nesse embate aparente. Para estruturar com precisão o centro da problemática, far-se-á, a partir da dignidade humana e da liberdade, uma constituição da concepção de autonomia privada, ao mesmo tempo em que o delineamento das molduras estatais fará o mesmo quanto às intervenções do Estado, principalmente o paternalista.

Os sustentáculos teóricos iniciais servirão como suporte para questionamentos específicos, a partir dos quais se tentará demonstrar a necessidade da criação de critérios limitativos a serem estabelecidos, de maneira que, ao final, possam-se considerar políticas públicas diferenciadas quanto à postura estatal em relação a algumas dessas problemáticas, visando sanar questões público-privadas através de intervenções preventivas na sociedade.

No contexto do Estado Democrático de Direito, a autonomia privada deve ser ponderada com outros interesses constitucionais, porém, o paternalismo estatal também carece de limitações, para não se sobrepor ao livre desenvolvimento do ser humano. Nesse sentido, é possível sustentar que a consolidação de critérios pode apontar caminhos diferenciados às políticas públicas de natureza preventiva (e não restritivo-punitiva), dando novas soluções a problemas sociais?

O objetivo desta pesquisa é delinear os limites de intervenção do Estado, principalmente o paternalista, na autonomia privada dos cidadãos, com o objetivo de nortear os rumos do desenvolvimento da personalidade humana na sociedade contemporânea, bem como criticar algumas situações específicas, com base em uma visão constitucionalizada, propondo políticas públicas em direção oposta àquelas apresentadas atualmente em relação às mesmas situações fáticas. 


\section{A dignidade humana e a constitucionalização do direito}

Toma-se como ponto de partida deste estudo as mutações evolutivas sofridas pelo Estado constitucionalista, que, com o passar do tempo, alterou-se até chegar ao modelo atual. Algumas das suas etapas de transição podem ser claramente delimitadas, citando-se aqui apenas as mais relevantes para a compreensão do tema. A fase inicial foi a liberal, com a dissociação entre o indivíduo e o ente público, numa clara manifestação em prol da liberdade e da independência privada (perfil individualista) (FACCHINI NETO, 2010). Na época, a visão negativa do Estado justificava essa aversão a ele, juntamente com seu afastamento (limitação ao poder político), apesar das inovações trazidas (direitos fundamentais e a democracia, por exemplo). Nessa fase, reside o germe dos ideais liberais dentro do Direito Civil, justificando o posicionamento de alguns autores durante o processo de constitucionalização, os quais defendiam a independência funcional do sistema privado, ou seja, a não afetação do Direito Civil, resultante do texto constitucional.

No ínterim entre o liberalismo estatal apresentado e a fase seguinte, consoante com o recrudescimento da intervenção (STRECK; MORAIS, 2001), ocorreram crises econômicas e guerras mundiais com resultados danosos à humanidade, possibilitando uma mudança de paradigma através do Estado Social de Direito, vislumbrando-se uma superação do individualismo a partir de um pensamento humano de crescimento conjunto da sociedade, com qualidade de vida. Garantias formais de direitos tornaram-se insuficientes; fazia-se necessária a materialidade, acompanhada de um benefício social de crescimento (MIRANDA, 2005).

Entretanto, somente com o Estado Democrático de Direito, vigente hoje no país, chegou-se a um modelo de força transformadora (com considerável poder normativo e ideológico) para materializar os interesses sociais constitucionalizados, buscando, com isso, a alteração da realidade e fazendo uso do poder público para uma vida digna e a plena efetividade constitucional. Especificamente no que tange o caso nacional, a construção do modelo democrático é um processo 
moroso e progressivo, do ponto de vista de fincar bases fortes com o constitucionalismo recente, pois o período de exceção (BONAVIDES, 2004) que o antecedeu enfraqueceu partes importantes do organismo social, dentre eles, o respeito e a importância da Constituição, tornando uma obrigação a recuperação desses elementos, especialmente pela importância da Carta Constituinte no progresso da nação.

Objetivando a reconstrução do ordenamento jurídico e dos rumos do país, firmou-se, no Brasil, a Constituição como elemento primordial desse ideal (supremacia da Constituição), reacendendo a chama do Direito como ciência interpretativa aberta, capaz de irradiar os efeitos constitucionais para toda a legislação vigente e a ser construída (SILVA, 2005). Pormenorizando, além da modificação da postura do Estado, o poder advindo do texto constitucional possibilitou uma direção a ser tomada (exemplo disso são as normas programáticas), a qual tem a pretensão de construir uma realidade diferenciada, ou seja, não há espaço para o simples crescimento econômico, dissociado de um upgrade social.

Alude-se a um princípio em especial a função de prisma irradiador de efeitos, denominado de dignidade da pessoa humana, servindo também de fundamento da República (CANOTILHO, 2004), bem como de norte a ser seguido na sociedade e no mundo jurídico. Cultuado na maioria dos textos constitucionais após a Segunda Guerra Mundial, esse princípio detém um alto grau de abstração, pois termos como "dignidade" são muito difíceis de serem conceituados. Porém, isso não impede que se compreenda a dignidade humana como um fundamento protetor do ser humano na sua condição de indivíduo único em sua existência, afastando qualquer tratamento do homem como objeto (influência da concepção kantiana) ${ }^{1}$.

\footnotetext{
"De qualquer modo, incensurável, isto sim, como teremos oportunidade de demonstrar no próximo segmento, é a permanência da concepção kantiana no sentido de que a dignidade da pessoa humana, esta (pessoa) considerada como fim, e não como meio, repudia toda e qualquer espécie de coisificação e instrumentalização do ser humano". Em igual sentido a posição de Rodriguez (2007, p. 45-46).
} 
Independentemente de sua densidade ou complexidade, seu poder de influenciar a totalidade do ordenamento jurídico não fica prejudicado, visto que, diante dos casos concretos, reconhecemse agressões à dignidade da pessoa humana, demonstrando-se ser mais fácil reconhecê-la do que defini-la. Em igual sentido, sendo os princípios constitucionais descendentes de uma matriz, a dignidade humana, gera-se, por consequência, uma ofensa indireta quando os demais princípios e direitos fundamentais são lesionados. Dessa forma, a conexão existente reforça a ideia de efetivação da Constituição, pois essas normas originadas na dignidade têm o condão de concretizar valores ou aspectos inerentes à própria ideia aduzida pelo princípio matriz (SARLET, 2008).

Seguindo uma visão de concretização de direitos e garantias fundamentais em todos os ramos do Direito por meio do princípio da dignidade, adere-se a este uma dupla função: limitadora e prestacional. A primeira, de condão negativo, restringe as ações entre particulares e do próprio poder estatal; a segunda apresenta o lado positivo, na busca da concretização de uma existência digna ao cidadão (CARVALHO, 2007).

A dupla função apresentada para o princípio representa dois aspectos relevantes à temática (principalmente a dimensão negativa). A priori, ao falar-se em restrição de ações entre particulares, encontrase o substrato da dignidade para aplicação dos direitos fundamentais nessas relações (eficácia dos direitos fundamentais interprivados), visando impedir o desamparo do indivíduo ou a violação de seus direitos constitucionais. A faceta restante aduz a restrição do próprio Estado para demarcar limites à sua intervenção, seja na sociedade ou na esfera privada dos indivíduos (tentativa de evitar abusos do poder estatal).

Os efeitos e funções citados denotam a natureza densa da dignidade humana, bem como indicam a base de onde emana o poder modificativo constitucional, servindo bem ao propósito de sustentar a supremacia da Constituição como pedra fundamental de uma renovação no Estado e Direito brasileiros. Embora existam críticas a serem apresentadas ao Estado, ainda restam determinados esclarecimentos a serem feitos, a fim de pormenorizar o conflito. 
Conforme se frisou anteriormente, a irradiação dos efeitos constitucionais alastrou-se por todos os campos jurídicos, mas, especificamente na esfera privada, houve resistência a essa invasão, pois se entendia pela autonomia do sistema privado (pensamento alinhado ao perfil do Estado Liberal) diante do texto magno. No entanto, pouco a pouco, a resistência foi sendo superada, ocasionando um novo olhar sob alguns dogmas civilistas, como a dicotomia entre público e privado, relativizada pelos fenômenos da privatização do público e publicização do privado (MAGALHÃES FILHO, 2002) ${ }^{2}$. Devido a esse novo enfoque, convencionou-se chamar de constitucionalização do direito privado a totalidade de mudanças resultantes na área privada, fruto da influência constitucional (SARMENTO, 2010).

Esse novo capítulo na história do Direito trouxe benefícios ao direito privado, seja pela inserção de valores relevantes, como a dignidade humana, para um regramento econômico-social adequado ou pela oportunização do retorno da hermenêutica à ciência jurídica (BARROSO, 2006; REIS; FISCHER, 2006) - o importante é a extensão de seus efeitos ${ }^{3}$. A hermenêutica tem papel de destaque nesta pesquisa, pois o pensamento filosófico (a hermenêutica filosófica de pensadores como Heidegger e Gadamer) que invadiu as fundações interpretativas constitucionais modernas é o suporte conjunto na releitura constitucionalizada do direito e da própria crítica a ser disposta (STRECK, 2001).

Complementa esse posicionamento as palavras de Streck (2005, p. 33) e Perlingieri (2008).

Ressalta a importância da dignidade humana, bem como seus efeitos no ordenamento privado, o autor Gustavo Tepedino (2007, p. 316): "Com efeito, vive-se hoje cenário bem distinto: a dignidade da pessoa humana impõe transformação radical na dogmática do direito civil, estabelecendo uma dicotomia essencial entre as relações jurídicas existenciais e as relações jurídicas patrimoniais. Consagrada como valor basilar do ordenamento jurídico, a dignidade da pessoa humana, esculpida no art. $1^{\circ}, \mathrm{III}, \mathrm{CF}$, remodela as estruturas e a dogmática do direito civil brasileiro, operando a funcionalização das situações jurídicas patrimoniais às existenciais, de modo a propiciar o pleno desenvolvimento da pessoa humana. Assim, torna-se obsoleta a summa divisio que estremava, no passado, direito público e direito privado bem como ociosa a partição entre direitos reais e direitos obrigacionais, ou entre direito comercial e direito civil, ambas fundadas nos aspectos estruturais das situações jurídicas subjetivas, não já nos seus aspectos funcionais". 
Assim, presume-se que as consequências constitucionais não cessaram, elas estão em contínuo processo de efetivação. Tendo em vista o desenvolvimento hermenêutico, o potencial constitucional modificativo é inesgotável na construção do novo panorama jurídico nacional. Retrato dessas afirmações é que a linha de pensamento explicitada deve ser seguida não somente pelo Judiciário, mas também pelos demais poderes, ou seja, o legislador tem o dever de seguir a senda constitucional, buscando efetivar os direitos fundamentais.

O vínculo entre a Constituição e os demais poderes na estruturação do ordenamento jurídico, incluindo-se as relações particulares, pode ser vislumbrado em institutos como a função social da propriedade ou na função social do contrato, em que o legislador encarrega-se de prever, por exemplo, a possibilidade de revisão de um contrato excessivamente oneroso. Esse posicionamento expõe a impossibilidade da manutenção do pensamento dos direitos fundamentais unicamente como defesa contra o Estado, tornando imperioso o reconhecimento de sua perspectiva subjetiva e objetiva (PEREIRA, 2006), juntamente a uma aplicação interprivatos.

Ao falar-se sobre efetivação dos direitos nessas relações, aludese o posicionamento deste estudo em prol da eficácia direta (SARLET, 2007), seguindo um raciocínio alinhado ao Supremo Tribunal Federal brasileiro, bem como um desejo pela máxima efetivação constitucional na órbita privada. Justifica-se a posição adotada não somente pelas benfeitorias advindas da Constituição, mas também pela impossibilidade de pleitear a proteção civil ao indivíduo na problemática proposta, sem sustentar fortemente seus direitos fundamentais.

\section{Autonomia privada x paternalismo: considerações de pesquisa e projeções a respeito de políticas públicas}

Retomando-se a ideia de reestruturação de institutos jurídicos a partir dos fundamentos constitucionais, em conjunto com o esforço em prol dos direitos fundamentais, pode-se passar a analisar a autonomia 
da vontade ou autonomia privada (LIMA, 2003). Salta aos olhos a conexão dela com a liberdade individual e, consequentemente, com a dignidade humana (a liberdade compõe a noção nuclear de mínimo existencial) (SARLET, 2006), partindo da imperiosidade do ideal de autodeterminação do ser humano (dimensão positiva) e impedindo o seu constrangimento (dimensão negativa). Aduz-se "que o homem, por natureza, é um ser livre e racional. A liberdade e a consciência são atributos fundamentais da pessoa humana, por meio dos quais o homem se torna capaz de escolher suas atividades e avaliar as conseqüências de seus atos" (GURGEL, 2006, p. 10-11).

A importância da liberdade como interesse humano fundamental vem desde períodos antigos, conforme deixa claro o pensamento de Koselleck (1999, p. 23): "o astuto refugia-se nos recantos secretos de seu coração, onde permanece seu próprio juiz, ao passo que os fatos externos devem ser submetidos ao juízo e ao tribunal do soberano". Essa passagem faz alusão ao único lugar no qual o homem era livre no Estado absolutista que precedeu o modelo liberal abordado no início deste trabalho, demonstrando que a própria liberdade foi uma conquista árdua através dos tempos. Ademais, segundo a visão de Kant, que pode ser apontado como integrante filosófico do Estado de Direito, a situação jurídica do cidadão está vinculada a alguns aspectos, dentre eles, a liberdade como indivíduo para racionalmente tomar suas decisões (GORCZEVSKI; SILVA JÚNIOR; LEAL, 2007).

Corroboram com a correlação entre dignidade e liberdade as seguintes palavras de Martínez (2005, p. 55):

La dignidad humana es el fundamento de la ética pública. Ésta, como paradigma político y jurídico de la modernidad, está conformada por cuatro grandes valores: la libertad, la igualdad, la solidaridad y la seguridad jurídica. La idea de dignidad humana, para su realización a través de la vida social, inseparable de la condición humana, se plasma en esos cuatro valores, cuyo núcleo esencial lo ocupa la libertad, matizada y perfilada por la igualdad y la solidaridad, en un contexto de seguridad jurídica. 
Os termos "autonomia da vontade" e "autonomia privada" são costumeiramente utilizados como sinônimos, porém, há autores que os distinguem, pondo em evidência que a autonomia da vontade recebeu nova interpretação através do prisma constitucional lançado, tomando a forma atual de autonomia privada (FARIA, 2007). Esta detém um caráter mais objetivo, distinguindo-se da antecessora, que apresentava certa vagueza e subjetividade em seus contornos. Cita-se também a existência de entendimentos diferenciados a respeito das concepções aqui defendidas, pois há na doutrina posicionamentos a fim de imputar à autonomia privada um conceito mais restrito, tratando especificamente de relações particulares, sendo a autonomia da vontade uma espécie mais ampla.

A noção de autonomia da vontade sofreu um processo de mutação em decorrência de diversos fatores, como as alterações estatais, a Constituição ou os conteúdos axiológicos assimilados pela humanidade, levando a um conceito moderno de autonomia privada (sentido amplo), o qual compreende desde decisões existenciais determinantes no desenvolvimento da personalidade humana até resoluções negociais entre particulares (SARMENTO, 2010) ${ }^{4}$.

Dito isso, passa-se a analisar o princípio que, devido à sua denominação, pode ter parcela de seu sentido alcançado, visto que a précompreensão da autonomia liga diretamente à liberdade (FERREIRA, 1999), bem como a uma independência pessoal por parte do indivíduo. Apesar da delimitação do posicionamento, cabe referir a definição comumente utilizada, na qual o link principal advém das preocupações patrimoniais, conforme aduz as palavras de Penteado (2007, p. 297):

considerando o direito como uma organização complexa de normas, a autonomia privada, dentro do quadro geral de normas, consiste num poder de o indivíduo gerar preceitos jurídicos individuais a regrar seu próprio cenário jurídico, em diferentes sentidos, com maior ou menor projeção

4 Adicionam-se as concepções fornecidas na obra de Ferri (1959, p. 5). 
social. A autonomia significaria a independência de normas superiores para geração, independência empírica e científica, na medida em que sem o ato não haveria a criação e de que esta é meramente reconhecida e aceita pelas normas preexistentes, ainda que tenham, como as normas de validade, uma função de controle.

Devido à latente preocupação com as questões monetárias, visualiza-se que a nova roupagem dada à autonomia da vontade manteve a proteção decisória nos rumos da vida privada em sentido patrimonial, mas houve uma diminuição no seu poder, com a limitação constitucional através de ferramentas como a função social do contrato (modificação interna/subjetiva) (FARIA, 2007). Em contrapartida, reforçou-se a dimensão existencial do princípio, por meio da carga valorativa e das normas constitucionais, a fim de alocar o homem em sua dignidade como centro do ordenamento jurídico na esfera privada, deixando o perfil individualista do liberalismo para abraçar um novo ideal de crescimento econômico-social (SARMENTO, 2010)5.

Há limitações a esse princípio, tendo em vista inexistirem definições absolutas, congeladas no tempo, dentro de um Estado Democrático de Direito, pois a proposta de uma Constituição aberta, possibilitando à hermenêutica o seu papel, não significa confundir liberdade com libertinagem. A licitude e a valoração são requisitos para a atuação dentro das previsões do ordenamento, impedindo o abuso da esfera individual com lesão ao aspecto coletivo-social.

A nova visão da autonomia privada conecta-se facilmente com os princípios constitucionais, como a dignidade humana e a liberdade, e com o fenômeno da constitucionalização do direito privado, objetivando a proteção de interesses próprios, porém, sem que para tal restem

Em igual sentido a posição de Faria (2007, p. 64): "Cabe ressaltar, então, que o Direito volta-se, hoje, para a valorização da pessoa como centro do ordenamento jurídico, devendo o Estado garantir ao ser humano as condições necessárias para o exercício desse poder de autodeterminação, como, por exemplo, as condições materiais mínimas de existência, sem as quais torna-se inviável o exercício da liberdade, entendida em seu sentido positivo". 
terceiros prejudicados. Portanto, a autonomia privada ainda é capaz de servir como sustentação teórica, contrariando posições abusivas por parte do Estado, sendo o enfoque seguinte o elemento faltante na equação crítica da problemática.

Nesse ponto, importantes elementos já estão presentes para a análise capital, entretanto, faltam alguns quesitos a serem elucidados, como a intervenção estatal, a qual se sustenta nos limites impostos pela Constituição, autonomia privada e manutenção da ordem social. Sinteticamente, o Estado, compreendido em sua faceta democrática de direito, tem o dever de efetivar os direitos fundamentais, fazendo uso de sua máxima capacidade para isso, sem, contudo, abusar de seus poderes. A força coercitiva detida pelo ente público se legitima não somente pela força, mas pela corroboração política (CADEMARTORI, 1999), ou seja, o Estado pode intervir junto aos indivíduos por estar legitimado constitucionalmente (e politicamente).

Na ótica privada, além dos fundamentos constitucionais (dignidade humana, liberdade etc.), levanta-se sempre a autonomia privada como limite a essa intervenção, desde que não haja ilicitude na relação jurídica ou dano a terceiros. Todavia, existem as possibilidades de abuso dos instrumentos estatais, compactuando com medidas autoritárias ou, no caso específico deste artigo, ações de cunho paternalista.

O paternalismo (DWORKIN, 2011) caracteriza-se por tentar proteger o indivíduo de si mesmo, impedindo um comportamento autolesivo, tratando o adulto como se fosse criança, negando-lhe a autonomia volitiva, em prol da própria proteção. Trata-se de uma posição claramente antiliberal e o conceito engloba a proteção dos mais vulneráveis ou daqueles que não podem proteger sua integridade (grupos de risco) (FEINBERG, 1986). A maioria das ações estatais paternalistas encontra-se em consonância com a primeira parcela da definição (já que a segunda parte está de acordo com a defesa dos direitos fundamentais), tendo um cunho de reprovação moral que não se sustenta, pois a aplicação de uma moral à coletividade é incompatível com o respeito à autonomia privada do cidadão. Nesse sentido, coadunam as palavras de Sarmento (2003, p. 296): 
Não cabe ao Estado, a qualquer seita religiosa ou instituição comunitária, à coletividade ou mesmo à Constituição estabelecer os fins que cada pessoa humana deve perseguir, os valores e crenças que deve professar, o modo como deve orientar sua vida, os caminhos que deve trilhar. Compete a cada homem ou mulher determinar os rumos de sua existência, de acordo com suas preferências subjetivas e mundividências, respeitando as escolhas feitas por seus semelhantes. Esta é uma ideia central ao Humanismo e ao Direito Moderno. De fato, cumpre recordar que os Poderes Públicos não a possuem e estão jungidos de forma diferente à ordem jurídica, pois só podem fazer o que ela determina ou autoriza. O princípio da legalidade, sob viés estatal, assume compostura mais rigorosa no afã de, por um lado, refrear o arbítrio estatal em benefício da liberdade individual e, por outro, condicionar o exercício do poder ao consentimento dos governados, manifestado através da lei aprovada por seus representantes. Já os particulares são titulares de uma esfera de liberdade juridicamente protegida, que deriva do reconhecimento da sua dignidade.

Outrossim, entende-se ser viável a intervenção estatal junto ao indivíduo para evitar uma lesão a terceiros (MILL, 2002) ${ }^{6}$, mas não é aceitável a restrição a ataques contra si mesmo ou sua vontade moral (FELDENS, 2008) ${ }^{7}$, exceto nos casos em que a ação degradar a própria condição de ser humano (ofensa à dignidade humana). Existem classificações dentro do paternalismo, no entanto, devido ao escasso espaço, será referida a mais comum delas, entre o paternalismo direto, o qual envolveria apenas uma pessoa (exemplo: suicídio), e o paternalismo indireto, caracterizado pela participação de duas pessoas (exemplo: eutanásia).

Obviamente, existem exceções ao posicionamento contra as ações paternalistas, nomeadas de paternalismo limitado, nas quais as

6 Comenta a respeito desse pensamento de Stuart Mill os autores Gorczevski, Silva Júnior e Leal (2007, p. 46-47).

7 Sobre esse tema, também se adiciona a construção de Avíles (2005, p. 88-90). 
ações estatais estariam legitimadas, mesmo contra vontade do cidadão. Exemplo disso são os casos de insanidade temporária, quando se pode agir para evitar um suicídio por parte de uma pessoa claramente fora de suas faculdades mentais. Essas ações por parte do Estado compactuam em parte com o próprio modelo adotado, visto que, na tentativa de efetivar os direitos fundamentais do cidadão, bem como protegê-lo, ele acaba ultrapassando seus limites e oprimindo a esfera volitiva individual.

Porém, apenas como ressalva, cabe aqui mencionar a necessidade de reflexão sobre esse tipo de intervenção, pois, no caso dos dependentes de entorpecentes, aduz-se como solução as chamadas internações involuntárias (dentro da proposta de política pública de combate às drogas), as quais nada mais são do que um ajuste de nomenclatura, com o objetivo de disfarçar o caráter opressivo e paternalista por parte do Estado. Desse modo, a observação crítica do confronto de interesses constitucionais contidos nessa situação é apenas um demonstrativo da atualidade e importância dos conflitos entre a autonomia privada e o paternalismo estatal.

Encaixando-se pouco a pouco na temática proposta, os elementos apresentados vão se unindo, pois a compreensão do modelo de Estado, associada aos princípios constitucionais e à busca por uma efetivação de direitos em todos os ramos, dentre eles, o direito privado, implica no questionamento de determinadas ações envolvendo a autonomia privada e o paternalismo estatal. Ante o exposto, algumas situações serão questionadas com base nas limitações a serem realizadas, com fulcro no suporte teórico supramencionado, fato facilitado a partir da visualização in concreto, a partir dos seguintes focos: a) situação fática de redução da dignidade humana (caso do anão); b) venda de órgãos; c) (casas de) prostituição; d) jogos de azar.

A escolha dessas situações tem como finalidade demonstrar a fragilidade teórico-jurídica das vedações na maior parte dessas condutas, galgadas em aspectos morais para conduzir os rumos das vidas de seus cidadãos. Não se está refutando o suporte moral, apenas se alude que ele não pode ser posto solitariamente, sem qualquer base 
jurídica, haja vista que a invasão estatal na autonomia não pode se dar de qualquer maneira, sem respeitar os fundamentos constitucionais.

Coaduna com tal crítica a ausência de efetividade mínima de determinadas normas jurídicas acerca das temáticas elencadas. A falta total de adimplemento é um elemento que pode afastá-la do mundo jurídico, conforme já entendia Kelsen (1998) nos tempos do positivismo jurídico. Portanto, há aqui a oportunidade para uma mudança de postura do ente público para com tais casos e, dentre os instrumentos possíveis a serem utilizados pelo Estado, far-se-á uso, neste estudo, das políticas públicas, a fim de alinhar o pensamento constitucionalizado com a realidade social brasileira, solucionando de outra forma esses problemas.

Entretanto, a proposição de políticas públicas requer esclarecimentos quanto à sua utilização, para dirimir determinados equívocos teóricos. Um dos erros comumente realizados parece ser oriundo de outro período histórico, já que a pressuposição de neutralidade de um ator político é tão falaciosa quanto à do intérprete do Direito, pois ambos detêm pré-compreensões que induzem o seu juízo e orientam suas ações (SCHMIDT, 2008). A partir desse primeiro passo, entendese que tanto o operador jurídico quanto o ente político que dimensiona uma política pública precisam ter um forte conhecimento constitucional, pois os efeitos irradiadores alcançam todos os poderes estatais. Um segundo equívoco sobre as políticas públicas é esclarecido por Bucci (2006, p. 11):

Finalmente, deve-se afastar, para um trabalho mais sistemático de busca de um conceito ou padrão de política pública para análise jurídica, a consideração de que todo direito é permeado pela política. Conquanto inegavelmente verdadeira essa assertiva, ela remete à distinção entre os termos em inglês politics e policy. Enquanto o primeiro se refere à atividade política em sentido amplo, o segundo conota os programas governamentais. E é desses últimos que se ocupa o presente estudo.

A especialidade assumida pelo estudo das políticas púbicas demonstra que a visão do Estado leviatânico já foi ultrapassada, 
estando o estudo em proposição pautado sob a índole constitucional e do Estado Democrático de Direito, no qual a combinação entre os entes sociais (Estado, sociedade civil e mercado) (ETZIONI, 2001) é imprescindível para se alcançar a realização de alternativas a condutas execradas moralmente, mas que não deveriam estar segregadas a uma ótica punitiva da autonomia privada.

Apesar dessa concepção combinada, o protagonismo do Estado se mantém na implementação das políticas públicas e na efetivação dos direitos constitucionais (BREUS, 2007), porém, ela não é mais unitária, subdividindo suas responsabilidades com a sociedade civil, reforçando a ideia de comunidade (poder local) (ETZIONI, 2001) para resolver determinadas questões. Todavia, para alcançar o desenvolvimento desejado e flagrantemente influenciado pelos ideais constitucionais, deve haver uma continuidade nos rumos determinados. Nesse ponto, localiza-se o prisma da Constituição como um norte a ser seguido, além do campo jurídico. Por essa razão, trabalha-se na direção de uma governabilidade constante (alterando a cultura política), independentemente das convicções ideológicas (mesmo sabendo da sua influência sob os atores políticos): "No Brasil, tem havido um esforço importante para reduzir a descontinuidade das políticas” (SCHMIDT, 2008, p. 2312).

Esse pensamento contínuo reproduz a expectativa social para com as ações dos entes públicos (e privados) na condução das ações que visam efetivar os mandamentos constitucionais ou tão somente adequar o pensamento jurídico aos contornos da realidade, sempre em um sentido mais profissional (KLIKSBERG, 1997), externando a importância de uma gerência social capacitada e preparada para essa tarefa, visto que, hoje, as políticas públicas possuem uma relativa densidade teórica, detendo critérios objetivos para a sua condução (sempre a partir de um pensamento constitucional $)^{8}$.

\footnotetext{
8 O autor aborda as fases das políticas públicas no seguinte artigo (SCHMIDT, 2008).
} 
Assim, os focos de crítica expostos são problemáticas que carecem desse esforço conjunto dos entes sociais, apresentando-se com reflexos públicos e privados. A proposição de políticas públicas coerentes com o prisma constitucional ${ }^{9}$ e com a realidade social são medidas adequadas ao tratamento inicial de algumas dessas questões, havendo a necessidade de um planejamento macro, que respeite a autonomia e, ao mesmo tempo, propicie uma existência digna ao bem estar individual e coletivo.

Por fim, apenas como demonstrativo inicial das proposições desta pesquisa, alude-se a uma proposta de política pública pensada para um dos temas citados, os jogos de azar (temática aprofundada em estudo paralelo) (DIAS, 2012), os quais, apesar do comportamento contrário por parte dos legisladores, que visam sua transformação em mais um ato ilícito (modificando seu panorama de contravenção para crime), apresentam-se em conformidade, no sentido da aceitação pela sociedade (sem contabilizar o proveito tributário para a população com a consequente legalização dos jogos).

Assim, uma primeira abordagem poderia ser informativa, evitando prejuízos a pessoas que desconheçam a essência dos jogos ou as suas possibilidades, acompanhada de uma orientação para aqueles diagnosticados como viciados ou adeptos compulsivos, encontrando na interdição civil um caminho mais suave e menos lesivo à autonomia dos indivíduos em seus direitos fundamentais (afastando a postura paternalista e deixando-a restrita aos casos de lesão a terceiros).

\section{Conclusão}

A proposta em tela faz parte de um estudo inicial, de maneira que ainda não auferiu resultados, estando, portanto, distante da concretização

O autor comenta sobre a necessidade de coerência nas políticas públicas, não sendo suficiente a análise econômica, devendo haver uma compactação institucional e jurídica também. (BREUS, 2007, p. 209). 
dos critérios desejados entre autonomia privada e paternalismo estatal. No entanto, o começo da pesquisa se dá com um considerável suporte teórico, a fim de impedir que inclinações morais sirvam como justificação ao cerceamento da autonomia dos cidadãos, permeando-se sempre por uma concepção constitucionalizada do direito pátrio.

Assim, com fulcro em ideais constitucionais como a dignidade e a liberdade, sustenta-se a autonomia privada como um direito fundamental essencial à consolidação da personalidade humana em toda a sua individualidade, não podendo ser conduzida pelo ente público a partir de argumentos paternalistas distantes do suporte jurídico-constitucional. Isso não significa a impossibilidade de intervenções estatais dessa espécie, e sim que elas devem estar devidamente ancoradas em argumentos jurídicos condizentes com um Estado Democrático de Direito.

Essa linha argumentativa busca a alteração de um panorama repressivo a partir da coalizão entre os entes sociais (Estado, mercado e sociedade civil) para se alcançar um patamar mais humano e preventivo, com o objetivo de auxiliar o crescimento pessoal dos indivíduos, sob o prisma constitucional-privado. Diante disso, com base na sustentação teórica apresentada, pautada pelo pensamento constitucional desejando tracejar as linhas interventivas do Estado nas trincheiras da autonomia privada, pode-se observar um caminho diferenciado a determinadas demandas sociais, retirando-as da penumbra punitiva e levando, por meio das políticas públicas, luzes às vielas escuras onde estão colocadas determinadas minorias da sociedade brasileira. Portanto, a determinação dos parâmetros entre os dois núcleos desta pesquisa pode trazer novas soluções a algumas demandas sociais brasileiras, sendo, por isso, importante a reflexão não apenas sobre as vias de fundamentação, mas visando o redirecionamento dos rumos da intervenção estatal nos direitos fundamentais. 


\section{Referências}

AVÍLES, Maria Del Carmen Barranco. Libertad. In: TAMAYO, Juan José (Dir.). 10 palabras clave sobre derechos humanos. Estella: Verbo Divino, 2005.

BARROSO, Luis Roberto. Fundamentos teóricos e filosóficos do novo direito constitucional brasileiro (pós-modernidade, teoria crítica e póspositivismo). In: BARROSO, Luis Roberto. (Org.). A nova interpretação constitucional: ponderação, direitos fundamentais e relações privadas. 2. ed. Rio de Janeiro: Renovar, 2006. p. 1-48.

BONAVIDES, Paulo. Teoria do Estado. 5. ed. São Paulo: Malheiros, 2004.

BREUS, Thiago Lima. Políticas públicas no Estado constitucional: problemática da concretização dos direitos fundamentais pela administração pública brasileira contemporânea. Belo Horizonte: Fórum, 2007.

BUCCI, Maria Paula Dallari. O conceito de política pública em direito. In: $\mathrm{BUCCl}$, Maria Paula Dallari (Org.). Políticas públicas: reflexões sobre o conceito jurídico. São Paulo: Saraiva, 2006. p.1-50.

CADEMARTORI, Sérgio. Estado de direito e legitimidade: uma abordagem garantista. Porto Alegre: Livraria do Advogado, 1999.

CANOTILHO, José Joaquim Gomes. Direito constitucional. 7. ed. Coimbra: Almedina, 2004.

CARVALHO, João Paulo Gavazza de Mello. Princípio constitucional penal da dignidade da pessoa humana. In: SCHMITT, Ricardo Augusto (Org.). Princípios penais constitucionais: direito e processo penal à luz da constituição federal. Salvador: JusPodivm, 2007. p. 277-327.

DIAS, Felipe da Veiga. Dignidade da pessoa humana e autonomia privada: a interdição civil aos jogadores (compulsivos) em contrapartida ao paternalismo estatal. In: REIS, Jorge Renato dos; LEÃO, Katia Cerqueira (Org.). Intersecções jurídicas entre o público e o privado: uma abordagem principiológica constitucional. Salvador: EDUFBA, 2012. p. 121-141. 
DWORKIN, Gerald. Paternalism. Disponível em: <http://stanford.library. usyd.edu.au/entries/paternalism/>. Acesso em: 19 jun. 2011.

ETZIONI, Amitai. La tercera via hacia una buena sociedad: propuestas desde el comunitarismo. Madrid: Mínima Trotta, 2001.

FACCHINI NETO, Eugênio. Reflexões histórico-evolutivas sobre a constitucionalização do direito privado. In: SARLET, Ingo Wolfgang (Org.). Constituição, direitos fundamentais e direito privado. 3. ed. Porto Alegre: Livraria do Advogado, 2010. p. 37-77.

FARIA, Roberta Elzy Simiqueli de Faria. Autonomia da vontade e autonomia privada: uma distinção necessária. In: NAVES, Bruno Torquato de Oliveira; FIUZA, César; SÁ, Maria de Fátima Freire de (Coord.). Direito civil: atualidades II: da autonomia privada nas situações jurídicas patrimoniais e existenciais. Belo Horizonte: Del Rey, 2007. p. 55-71.

FEINBERG, Joel. Harm to self: the moral limits of the criminal law. Oxford: Oxford University Press, 1986. v. 3.

FELDENS, Luciano. Direitos fundamentais e direito penal: garantismo, deveres de proteção, princípio da proporcionalidade, jurisprudência constitucional penal, jurisprudência dos tribunais de direitos humanos. Porto Alegre: Livraria do Advogado, 2008.

FERREIRA, Carlos Alberto Goulart. Equilíbrio contratual. In: LOTUFO, Renan (Coord.). Direito civil constitucional:cadernos 1. São Paulo: Max Limonad, 1999. p. 57-148.

FERRI, Luigi. L'autonomia privata. Milano: Dott. A. Giuffrè, 1959.

GORCZEVSKI, Clovis; SILVA JÚNIOR, Edison Botelho; LEAL, Mônia Clarissa Hennig. Introdução ao estudo da ciência política, teoria do estado e da constituição. Porto Alegre: Verbo Jurídico, 2007.

GURGEL, Fernanda Pessanha do Amaral. Liberdade e direito privado. In: NERY, Rosa Maria de Andrade. Função do direito privado no atual momento histórico. São Paulo: Revista dos Tribunais, 2006. p. 9-33.

KELSEN, Hans. Teoria pura do direito. 6. ed. São Paulo: Martins Fontes, 1998. 
KLIKSBERG, Bernardo. O desafio da exclusão: para uma gestão social eficiente. São Paulo: FUNDAP, 1997.

KOSELLECK, Reinhart. Crítica e crise: uma contribuição à patogênese do mundo burguês. Rio de Janeiro: Contraponto, 1999.

LIMA, Taisa Maria Macena de. Princípios fundamentais do direito civil atual. In: NAVES, Bruno Torquato de Oliveira; FIUZA, César; SÁ, Maria de Fátima Freire de (Coord.). Direito civil: atualidades. Belo Horizonte: Del Rey, 2003. p. 241-258.

MAGALHÃES FILHO, Glauco Barreira. Hermenêutica e unidade axiológica da constituição. 2. ed. Belo Horizonte: Mandamentos, 2002.

MARTÍNEZ, Gregorio Peces-Barba. Dignidad humana. In: TAMAYO, Juan José (Dir.). 10 palabras clave sobre derechos humanos. Estella: Verbo Divino, 2005. p. 10-24.

MILL, Stuart. On liberty. New York: Dover, 2002.

MIRANDA, Jorge. Teoria do Estado e da Constituição. Rio de Janeiro: Forense, 2005.

PENTEADO, Luciano de Camargo. Autonomia privada e negócio jurídico: breves notas. In: PÜSCHEL, Flavia Portella (Org.). Organização das relações privadas: uma introdução ao direito privado com métodos de ensino participativos. São Paulo: Quartier Latin, 2007. p. 293-307.

PEREIRA, Jane Reis Gonçalves. Apontamentos sobre a aplicação das normas de direito fundamental nas relações jurídicas entre particulares. In: BARROSO, Luís Roberto (Org.). A nova interpretação constitucional: ponderação, direitos fundamentais e relações privadas. 2. ed. Rio de Janeiro: Renovar, 2006. p.119-192.

PERLINGIERI, Pietro. A doutrina do direito civil na legalidade constitucional. In: TEPEDINO, Gustavo (Org.). Direito civil contemporâneo: novos problemas à luz da legalidade constitucional. São Paulo: Atlas, 2008. p.1-11. 
REIS, Jorge Renato dos; FISCHER, Eduardo. Hermenêutica para vinculação dos particulares a direitos fundamentais. In: LEAL, Rogério Gesta; REIS, Jorge Renato dos (Org.). Direitos sociais e políticas públicas: desafios contemporâneos. Santa Cruz do Sul: Edunisc, 2006. t. 6, p.1643-1675.

RODRIGUEZ, Javier Llobet. Derechos humanos y justicia penal. Heredia: Poder Judicial, 2007.

SARLET, Ingo Wolfgang. Dignidade da pessoa humana e direitos fundamentais na constituição federal de 1988. 5. ed. Porto Alegre: Livraria do Advogado, 2008.

SARLET, Ingo Wolfgang. Direitos fundamentais e direito privado: algumas considerações em torno da vinculação dos particulares aos direitos fundamentais. Revista Jurídica, Porto Alegre, ano 55, n. 352, p.193-259, 2007.

SARLET, Ingo Wolfgang. Direitos fundamentais sociais, "mínimo existencial" e direito privado: breves notas sobre alguns aspectos da possível eficácia dos direitos sociais nas relações entre particulares. In: SARMENTO, Daniel; GALDINO, Flavio (Org.). Direitos fundamentais: estudos em homenagem ao professor Ricardo Lobo Torres. Rio de Janeiro: Renovar, 2006. p. 551-602.

SARMENTO, Daniel. Direitos fundamentais e relações privadas. 2. ed. Rio de Janeiro: Lúmen Juris, 2010.

SARMENTO, Daniel. Os princípios constitucionais da liberdade e da autonomia privada. In: LEITE, George Salomão. Dos princípios constitucionais: considerações em torno das normas principiológicas da constituição. São Paulo: Malheiros, 2003. p. 294-341.

SCHMIDT, João Pedro. Para entender as políticas públicas: aspectos conceituais e metodológicos. In: REIS, Jorge Renato dos; LEAL, Rogério Gesta (Org.). Direitos sociais e políticas públicas: desafios contemporâneos. Santa Cruz do Sul: Edunisc, 2008. v. 8, p. 2307-2333.

SILVA, Virgílio Afonso da. A constitucionalização do direito: os direitos fundamentais nas relações entre particulares. São Paulo: Malheiros, 2005. 
STRECK, Lenio Luiz; MORAIS, José Luis Bolzan de. Ciência política e teoria geral do estado. 2. ed. Porto Alegre: Livraria do Advogado, 2001.

- A hermenêutica filosófica e as possibilidades de superação do positivismo pelo (neo)constitucionalismo. Estudos jurídicos, São Leopoldo, v. 38, n. 1, p. 22-35, jan. /abr. 2005.

- Hermenêutica jurídica $\mathbf{e}(\mathbf{m})$ crise: uma exploração hermenêutica da construção do direito. 3. ed. Porto Alegre: Livraria do Advogado, 2001.

TEPEDINO, Gustavo. Normas constitucionais e direito civil na construção unitária do ordenamento. In: SOUZA NETO, Cláudio Pereira de; SARMENTO, Daniel (Coord.). A constitucionalização do direito: fundamentos teóricos e aplicações específicas. Rio de Janeiro: Lúmen Juris, 2007. p. 309-320.

Recebido em: 00/11/13

Aprovado em: 00/12/13 